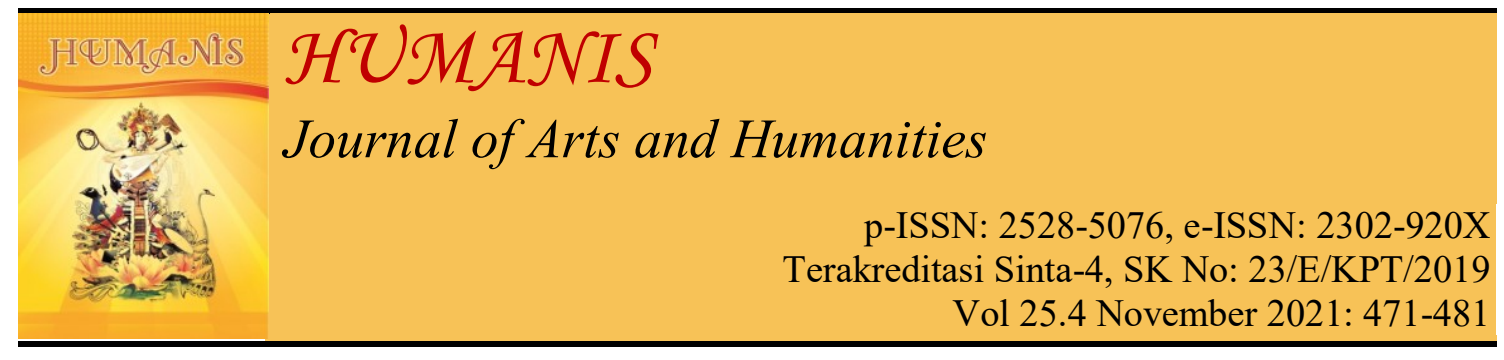

\title{
Lavender Linguistics: Lexicon Used by Gay People in Bali For the Topic of Preferences
}

\author{
Maryon Renaldy \\ Udayana University, Denpasar, Bali, Indonesia \\ Correspondence email: ayonrenaldy@gmail.com
}

\begin{tabular}{|c|c|}
\hline Article Info & Abstract \\
\hline $\begin{array}{l}\text { Submitted: } 10^{\text {th }} \text { August } 2021 \\
\text { Revised: } 24^{\text {th }} \text { September } 2021 \\
\text { Accepted: } 15^{\text {th }} \text { October } 2021 \\
\text { Keywords: } \\
\text { Lavender Linguistics, Lexicon, } \\
\text { gay people. } \\
\text { Corresponding Author: } \\
\text { Maryon Renaldy } \\
\text { email: } \\
\text { ayonrenaldy@gmail.com } \\
\text { DoI: } \\
\text { https://doi.org/10.24843/JH.20 } \\
\text { 21.v25.i04.p07 }\end{array}$ & $\begin{array}{l}\text { This study aims to find out the lexicon and its meanings used by } \\
\text { gay people in Bali for the topic of preference. The data was } \\
\text { collected through qualitative methods by interviewing } \\
\text { informants, recording, and note-taking as well as doing } \\
\text { participatory observation to gay people from several places, } \\
\text { nightclubs, and communities in Bali including Balijoe, and } \\
\text { Mixwell bar in Seminyak, and Bali Peace Crew Community in } \\
\text { Denpasar. The data was qualitatively analyzed and } \\
\text { descriptively presented based on lavender linguistics, which } \\
\text { according to William Leap, is a study about the language used } \\
\text { by the queer community to communicate. The theories used are } \\
\text { sociolinguistics theories proposed by Yule which are slang and } \\
\text { speech varieties. It resulted in } 10 \text { lexicons were used by gay } \\
\text { people in the level of word, phrase, and abbreviation to } \\
\text { exchange information or communicate with the interlocutors. } \\
\text { The meanings of each lexicon are influenced by participants, } \\
\text { setting, topic, and function. }\end{array}$ \\
\hline
\end{tabular}

\section{INTRODUCTION}

Sociolinguistics is the study of the relationship between language and society. (Holmes, 2017). It also examines and explores the relation of a language with society through social factors such as lifespan, origin, social class, gender, etc. (Morgan, 2003). As well as concerned about how language is used among the different social groups in different social situations for communication purposes (Georgieva, 2014). Since there is a lot of group of people inside a society, thus the way they are using language is different one another. The different language variations might be used by the people following the gender, age, education, profession, ethnic origin, etc. (Holmes,2013). One of the groups in a society is the gay people. According to American Psychological Association (2008), Gay is a man who is an enduring pattern of emotional, romantic, and/or sexual attraction to other men. This group is rejected by most of the society in Indonesia, therefore some discrimination is given to them. To show their identities and the relation with the interlocutors between the members of the group of gay people without being discriminated against, they use a certain kind of lexicons. These lexicons are called lavender lexicons and are used through 
the way they are talking to each other for some topics, including the topic of preferences. Lavender lexicon is studied under the area of Lavender linguistics. Leap through his book "Beyond the Lavender Lexicon" explained that Lavender linguistics is a study about the language used by the community of lesbian, gay, bisexual, and transgender to communicate. (Leap, 1995). It is also the study of the communicative practices and the language of the LGBTI (Lesbian, Gay, Bisexual, Transgender, and intersex) community (Rudwick,2010:128). The term lavender emerging as a name for the community because lavender is associated with LGBT rights (Cage,2003:1). Lavender Linguistics is a subsection of sociolinguistics that has built on issues from queer studies that sexual and gender identities are constructed. Lavender linguistic is based on Queer Theory, the philosophical analytical viewpoint which questions all sexual and gender identity labels, whether biological or whether socially constructed. (Butler,2004:7). Meanwhile, Adihartono explained that Lavender linguistics is a subsection of a sociolinguistic that was shaped from identified and constructed sexual and communication (Adihartono,2016:7). Therefore, simply, it could be explained that Lavender linguistics is a subfield of sociolinguistics in practical studies of certain types of language used by the Lesbian, Gay, Bisexual, and Transgender people to communicate with each other. Related to that, the kind of lexicon used by gay people is only understood by the persons inside the queer community since it contains implied meaning used in communication to deliver information from a person to the interlocutor. The use of these lexicons is quite different from how it is used in common English. Like on the following example of a conversation between two gay persons.
This is also the phenomenon of how the lavender lexicon itself was used.

A : Are you a Bear?

B : Yes, I am.

A : So, Do you like Twink?

B : Yes, I do.

When used by gay people the lexicon Bear does not refer to an animal, however, it refers to a hairy man with a muscular body. Meanwhile, the lexicon Twink is used to describe a slender, hairless, typically younger gay man.

Based on the explanation above the problems for this study can be formulated as follows: What are the lexicons used by gay people in Bali for the topic of preferences?, What are the meanings of those lexicons when it was used in order communicate each other?

Moreover, this research is carried to find out the use of the Lavender lexicon, for lavender linguistics study, when it was used by the gay people in Bali to exchange information when talking about the topic of preferences.

\section{METHOD AND THEORY}

This study was field research including the interview, recording, and note-taking. The method used is classified as descriptive qualitative method. Descriptive Qualitative study is a comprehensive summarization, in everyday terms, of specific events experienced by individuals or groups of individuals. (Lambert \& Lambert, 2012). The goal is to describe the phenomenon as well as its characteristics (Nassaji, 2015).

The data source for this study was taken from the informants that were determined and accounted for based on purposive sampling. Purposive sampling is defined as an approach of a strategy where members of a sample are chosen with a purpose to represent a location or type concerning the criterion. (Richie et al, 2003). Thus, the criterion for the 
informants are gay people, 18 years old or older, Indonesians or foreign people who can speak English, are trustworthy, and are responsible. The amount of respondents is 5 persons and is considered to represent the whole population of gay people in Bali. The data was collected from several places and communities including nightclubs, those are Balijoe, and Maxwell, in Seminyak, and also from Bali Peace Crew Community in Denpasar.

Data were taken through direct interviews with the informants based on the interview guide. The interview was used to gather information one-on-one using a series of predetermined questions or a set of interest areas (Paradis et al, 2016). During the interview, the conversation was recorded and transferred into text by note-taking after the interview with the informants. The interview was carried out in an informal situation with the informants to make them feel comfortable; therefore they are not rejecting the answer to the question. The other method for collecting data used for this study is an observation one, which is defined as watching and observe how the lavender lexicon was used by gay people. It involves participatory observation, which is the process enabling the researcher to learn about the activities of the people understudy in the natural setting through observing and participating in those activities. It provides the context for the development of sampling guidelines and interview guides (DeWALT \& DeWALT, 2002). The participatory observation was carried out by doing the usual conversation with the informants and then the dialogue was recorded to get the data necessary for the study. After the moment of recording, the dialogue collected from the gay people was transferred to the text type of data by note-taking to collect the lavender lexicons used inside the conversation.
All of the data that has been collected was analyzed through a qualitative-based method for the lexicons found from the field. The data analysis was described with the following steps of classifying, reducing/eliminating, and the analysis of the user as well as the meaning. It was carried out by classifying how the lexicon is used according to the topic and descriptively analyzed to find the meaning, as well as the context of how it was used.

The result and data analysis were presented descriptively in the method of descriptive qualitative; to show how the lavender lexicon is used by gay people based on how it was used for the topic of preferences. It is related to the context of conversation and meaning between a person and an interlocutor. The presentation was held in the form of words and sentences for each lexicon. Since many lexica have each meaning and are used according to the topic it was utilized also relates to the user as well, therefore each lexicon is presented in descriptive words and sentences.

\section{Literature Review}

The literature review for this study was related to the lavender linguistics studies. The first study is a scientific article entitled Gay Language and Indonesia: Registering Belonging by Boellstorff (2004). This article explained the use of Bahasa Gay (Gay Language) and was based on the Indonesian language. It found that the derivational processes were available for the Indonesian gay language e.g. the word Cuco was derived from the Indonesian lexicon Cakep means handsome. (Boellstorff, 2004). However, the infirmity was it did not describe and explain the derivational processes from those words. There were no processes that appear as well as the analysis just going straight to the lexicon and its 
meaning. Many words were analyzed inside the article and it has resulted in numerous example lexicons used by the gay community in Indonesia, including register and also the setting for each lexicon.

The second study is a scientific article titled Gay and Lesbian Language by Kulick (2000). The study aimed to describe how gay and lesbian people use language in the 1980s and 1990s (Kulick, 2000). To describe and found it, the qualitative method was used through the library study. The result was several lexicons found inside the conversation between gays and lesbians during the 1980s until the 1990s and it was only understood by them. The study had a very deep analysis from a sociolinguistic perspective related to how the gay and lesbian using the language inside the community through certain lexicons. However, the analysis didn't give any meaning to those lexicons used. Therefore, the meaning of each lexicon was not analyzed in the study. Accordingly, it would be better if the article contain the meaning analysis as well.

The third study is a thesis entitled Gay Language in Cape Town: A Study of Gayle - Attitudes, history, and usage by Luyt (2014). This thesis described how the Gay community and also Lesbian, Bisexual, and Transgender using their special language to communicate with each other. To find out the special language used by the communities, research methods of qualitative and quantitative were applied by using questionnaires and comparative study. Meanwhile, the analysis was carried out through the history and the history of the language itself. It result in the description also the explanation of how the Gay language was used in Cape Town and the reason why it was utilized. The reasons were including communicating with a friend, as an identification to be a part of the community, as well as making a joke as the users of the language (Luyt, 2014). The study also found that the gay language in Cape Town was used by many people from the lesbian, gay, bisexual, and transgender community in various kinds of educational levels i.e. high school, undergraduate student, etc., and race i.e. Caucasian, Negroid, mixed race, etc. This thesis explained very deeply the background of gay languages in Cape Town like the reasons why it was used, the speakers, and also the historical setting from a comparative study. However, the weakness is the explanation was not focusing deeply on the language itself in the internal perspective, such as lexicon, sentence, and language structure. Therefore it would be better if the study have deeper explanations about them.

\section{Theoretical Framework}

There are two kinds of sociolinguistic theories related to this study; those are slang and speech varieties.

\section{Theory of Slang}

Slang is used for a very informal speech variety which serves as an "ingroup" language such as teenagers, army, pop group, etc. (Yule, 2010). The word slang is used only by the group itself and has an informal language. The slang has been defined as one of those that everybody can recognize and nobody can define. Slang words almost could not be found in a dictionary. It is an informal, non-standard English vocabulary that provides an effective shortcut in expression because it is often vivid and sharp. Like idioms, slang is part of the native speaker's informal talk. Slang is traditionally considered as a vulgar, and rude form of language with a strong color 
of irreverence and yet vitality in a society. It is generally labeled as a linguistic taboo that should not be appearing on most formal social occasions (Yule, 2010). This theory was used to identify the lavender lexicons spoken by gay people in Bali.

\section{Theory of Speech Varieties}

Sociolinguistics is interested in the different types of speech variety used to express and reflect social factors. The social factors will prove important in describing and analyzing all kinds of interaction. In any situation, linguistic choices will generally reflect the influence of one or more of the following components. The components are (1) The participant, who is speaking and who they are speaking to, (2) The setting or social context of the interaction, where they are speaking, (3) Topic, what being, talking about, (4) the function, why they are speaking (Yule, 2010). This theory was used to analyze the meaning of lavender lexicons spoken by the gay people in Bali.

\section{RESULTS AND DISCUSSIONS}

Preference is a topic that refers to what someone likes and dislikes, including the body shape of a person, finances, and relationships. For this topic, the lexicon used by gay people and the meaning are descriptively described and analyzed in the following explanations.

\section{Bear}

Based on the oxford dictionary the lexicon bear means "be able to accept and deal with something unpleasant; be fit for something; take a responsibility for something; have particular feeling especially a negative feeling; support somebody or something; show something; carry something so it can be seen; give birth to a child; produce flower or fruits; go or turn in the direction mentioned; heavy wild animal with thick fur and sharp claws." (Oxford, 2017:33). However, when this lexicon was used by the gay community it refers to a hairy man with a muscular body. Since this lexicon's meaning is different from the one in the dictionary, thus according to the theory of slang by Yule (2010), this lexicon is identified as slang because the meaning was only known and used by the group of gay people. The other reason is the meaning itself could not be found in the dictionary; hence the lexicon was defined as an informal and non-standard English vocabulary that could not appear inside most formal situations. However, it gives an effective shortcut in expression. Therefore, rather than said a hairy muscular man, the group of gay people would simply use the lexicon bear, consequently, the people who do not belong to the group could not define the meaning although they still recognize the lexicon.

\section{Chubby}

Based on the oxford dictionary the lexicon chubby means "slightly fat" (Oxford, 2017:72). However, when this lexicon was used by the gay community it refers to a fat male who is enduring physical romantic and/or emotional attractions are to people of the same sex. Since this lexicon's meaning is different from the one in the dictionary, thus according to the theory of slang by Yule (2010), this lexicon is identified as slang because the meaning was only known and used by the group of gay people. The other reason is the meaning itself could not be found in the dictionary; hence the lexicon was defined as an informal and non-standard English vocabulary that could not appear inside most formal situations. However, it gives an effective shortcut in expression. Therefore, rather than said a gay fat male, which is a vivid, sharp, and irreverent utterance, the group 
of gay people would simply use the lexicon chubby, consequently, the people who do not belong to the group could not define the meaning although they still recognize the lexicon.

\section{Chubby chaser}

Based on the oxford dictionary the lexicon chubby means "slightly fat" (Oxford, 2017: 72) and the lexicon chaser means " a drink that you have after another of a different kind; a horse for steeplechase racing; a person who follows and chases somebody/something" (Oxford, 2021). Meanwhile, when both of these lexicons are combined and used together by the gay community then becoming a phrase that is a chubby chaser, it doesn't have the meanings which are a slight fat drink that you have after another of a different kind; a slight fat horse for steeplechase racing; and a slightly fat person who follows and chases somebody/something. Based on the theory of speech varieties proposed by Yule (2010) which is said that social factors express and reflect the speech varieties, thus the combination of lexicon chubby and chaser, which is a phrase when it was used by the gay community it has a different meaning. The lexicon chubby itself when it was used by the gay community, means a fat male who is enduring physical romantic and/or emotional attractions are to people of the same sex. Therefore, when the combination of these lexicons that is chubby and chaser was used by the gay community and becoming a phrase of chubby chaser, it refers to a person who is interested in a fat male who is enduring physical romantic and/or emotional attractions are to people of the same sex. Since the phrase's meaning is different from the one in the dictionary, thus according to the theory of slang by Yule (2010), it is identified as slang because the meaning was only known and used by the group of gay people. The other reason is the meaning itself could not be found in the dictionary; hence these lexicons, in form of a phrase, were defined as an informal type of language that could not appear inside most formal situations. However, it gives an effective shortcut in expression. Therefore, rather than said a person who interest in gay fat male, which is a vivid, sharp, and irreverent utterance, the group of gay people would simply use the phrase chubby chaser, consequently, the people who do not belong to the group could not define the meaning although they still recognize the combination of both lexicons.

\section{Twink}

Based on the oxford dictionary no lexicon twink could be found. However, when this lexicon was used by the gay community it has the meaning that is a teenager male usually from 17-22 years old. Since this lexicon's meaning could not be found in the dictionary, thus according to the theory of slang by Yule (2010), this lexicon is identified as slang because the meaning was only known and used by the group of gay people. The lexicon also was defined as an informal and non-standard English vocabulary that could not appear inside most formal situations for the reason it is not available in the dictionary. However, it gives an effective shortcut in expression. Therefore, rather than said a hairless slim body teenager male which is usually from 17-22 years old, the group of gay people would simply use the lexicon twink, consequently, the people who do not belong to the group could not define the meaning as well as they do not recognize the lexicon.

\section{Hunk}

Based on the oxford dictionary the lexicon hunk means "thick piece cut off something" (Oxford, 2017:217). 
However, when this lexicon was used by the gay community it refers to a man which is around the '20s and '30s and has a good-looking body. Since this lexicon's meaning could not be found in the dictionary, thus according to the theory of slang by Yule (2010), this lexicon is identified as slang because the meaning was only known and used by the group of gay people. The lexicon also was defined as an informal and nonstandard English vocabulary that could not appear inside most formal situations for the reason it is not available in the dictionary. However, it gives an effective shortcut in expression. Therefore, rather than said a good-looking body man around the '20s and '30s, the group of gay people would simply use the lexicon hunk, consequently, the people who do not belong to the group could not define the meaning as well as they do not recognize the lexicon.

\section{Cut}

Based on the oxford dictionary the lexicon cut means "make an opening or wound in something with something sharp; remove something from something larger with knife, etc.; divide something into two or more pieces; shorten by cutting it; be capable of cutting or being cut; reduce something; remove something from something; remove part of a text on a computer screen in order to place it elsewhere; prepare a film or a tape by removing part of it, etc.; edit something; stop film or recording; move quickly to one scene to another; stay a way from a class that you should go to; hurt somebody emotionally; cross another line; wound cause by something sharp; hole or opening made with a knife, etc.; reduction in amount, size, supply, etc.; act of cutting something; style in which clothes, hair, etc.; share in something; act of removing part of something; part that is cute from something larger " (Oxford, 2017:110,111). However, when this lexicon was used by the gay community it refers to a circumcised male genital. Since this lexicon's meaning is different from the one in the dictionary, thus according to the theory of slang by Yule (2010), this lexicon is identified as slang because the meaning was only known and used by the group of gay people. The other reason is the meaning itself could not be found in the dictionary; hence the lexicon was defined as an informal and non-standard English vocabulary that could not appear inside most formal situations. However, it gives an effective shortcut in expression. Therefore, rather than said a male genital that circumcised, which is a vivid, sharp, and irreverent utterance, the group of gay people would simply use the lexicon cut, consequently, the people who do not belong to the group could not define the meaning although they still recognize the lexicon.

\section{Uncut}

Based on the oxford dictionary the lexicon uncut means "left to grow; not cut short; left in it's complete form; without any parts remove; not censored; not given a shape by cutting; not cut into separate pieces" (Oxford, 2021). However, when this lexicon was used by the gay community it refers to an uncircumcised male genital. Related to the lexicon cut, when it was used by the gay community it refers to a circumcised male genital, thus on the contrary when it turns into the lexicon uncut the meaning will be vice versa that it refers to an uncircumcised male genital. Since this lexicon's meaning is different from the one in the dictionary, thus according to the theory of slang by Yule (2010), this lexicon is identified as slang because the meaning was only known and used by the group of gay people. The other reason is the meaning itself could not be found in 
the dictionary; hence the lexicon was defined as an informal and non-standard English vocabulary that could not appear inside most formal situations. However, it gives an effective shortcut in expression. Therefore, rather than said a male genital that uncircumcised, which is a vivid, sharp, and irreverent utterance, the group of gay people would simply use the lexicon uncut, consequently, the people who do not belong to the group could not define the meaning although they still recognize the lexicon.

\section{Sugar Daddy}

Based on the oxford dictionary the lexicon sugar means "sweet obtained from various something; added sugar to something" (Oxford, 2017:44), and the lexicon daddy means "father" (Oxford, 2017:111). Meanwhile, when both of these lexicons are combined and used together by the gay community then becoming a phrase that is sugar daddy, it doesn't have the meanings which are the father of the sweet which is obtained from various things; and the father who add sugar to something. Based on the theory of speech varieties proposed by Yule (2010) which is said that social factors express and reflect the speech varieties, thus the combination of lexicon sugar and daddy which is a phrase when it was used by the gay community it has a different meaning. Therefore, it refers to an older man who has a relationship with a younger boy and helps his younger partner financially. Since the phrase's meaning is different from the one in the dictionary, thus according to the theory of slang by Yule (2010), it is identified as slang because the meaning was only known and used by the group of gay people. The other reason is the meaning itself could not be found in the dictionary; hence these lexicons, in form of a phrase, were defined as an informal type of language that could not appear inside most formal situations. However, it gives an effective shortcut in expression. Therefore, rather than said an older man who helps his younger boy partner financially and has a relationship with, the group of gay people would simply use the phrase sugar daddy, consequently, the people who do not belong to the group could not define the meaning although they still recognize the combination of both lexicons.

\section{Sugar baby}

Based on the oxford dictionary the lexicon sugar means "sweet obtained from various something; added sugar to something" (Oxford, 2017:44) and the lexicon baby means "very young child or animal; word used affectionately to address your wife, husband or lover."(Oxford, 2017:26). Meanwhile, when both of these lexicons are combined and used together by the gay community then becoming a phrase that is sugar baby, it doesn't have the meanings which are the very young child of sweet obtained from various something; a very young child who added sugar from something; a word used affectionately to address someone's wife, husband or lover that is adding sugar into something. Based on the theory of speech varieties proposed by Yule (2010) which is said that social factors express and reflect the speech varieties, thus the combination of lexicon sugar and baby which is a phrase when it was used by the gay community it has a different meaning. Therefore, it refers to a younger boy having a relationship with an older man, and got support financially from his older partner. Since the phrase's meaning is different from the one in the dictionary, thus according to the theory of slang by Yule (2010), it is identified as slang because the meaning was only known and used by the group of gay people. The other reason is the 
meaning itself could not be found in the dictionary; hence these lexicons, in form of a phrase, were defined as an informal type of language that could not appear inside most formal situations. However, it gives an effective shortcut in expression. Therefore, rather than said a younger boy who got support financially from an older man and has a relationship with, the group of gay people would simply use the phrase sugar baby, consequently, the people who do not belong to the group could not define the meaning although they still recognize the combination of both lexicons.

\section{BF (Boyfriend)}

$B F$ is an abbreviation that stands for Boyfriend. According to the oxford dictionary, the lexicon boyfriend means "man or boy with whom somebody has a romantic and/or sexual relationship" (Oxford, 2017:47). However, when this abbreviation was used by the gay community it has the meaning that is a male partner of a male who is enduring physical romantic and/or emotional attractions are to people of the same sex. Since this lexicon's meaning is a little bit different from the one in the dictionary, thus according to the theory of slang by Yule (2010), this lexicon is identified as slang because the meaning was only known and used by the group of gay people. The other reason is the meaning itself could not be found in the dictionary; hence this lexicon, in the form of abbreviation, was defined as an informal and non-standard English vocabulary that could not appear inside most formal situations. However, it gives an effective shortcut in expression. Therefore, rather than said a male partner of a gay person, the group of gay people would simply use the abbreviation $b f$, consequently, the people who do not belong to the group could not define the meaning although they still recognize the shortened form of the lexicon.

Related to each lexicon used by the gay people in Bali will come to the meaning of them, based on the explanation above, because according to the theory of speech varieties proposed by Yule (2010), several components generally reflect and influence them. Those components are:

1. The participant: the speakers who are speaking and used this lexicon are gay people

2. The setting or social context of the interaction: the speakers who are speaking in the social media, public bar, house, or any place when they meet and/or having a conversation with the other speaker from the community

3. Topic: when the speaker talked about preferences.

4. The function: the speaker is speaking or having a conversation with the aims such as to know each other, deliver or exchange information, make a deal about sexual activities, and making a joke about something that relates to the speaker's preference.

Therefore, all of the lexicons have a different meaning from the ones inside the oxford dictionary, when it is used by the group of gay people, as well as it is only understood by the people inside the group itself.

\section{CONCLUSIONS}

Based on the analysis in the discussion, it could be concluded that there are 10 Lavender Lexicons were used by the gay people in Bali for the topic of preference. All of these lexicons were used in the level of word, phrase, and abbreviation. Related to the meaning of each lexicon, all of the 10 lexicons above are slang based on the theory of 
slang proposed by Yule (2010) because the meanings of these lexicons are different from the ones in the Oxford dictionary as well as could be not be found inside it. Because of these reasons, thus these lexicons were used by gay people in Bali to communicate and/or exchange information without being realized by the persons who do not belong to the group of gay people. Still related to the meaning of each lexicon, based on the theory of speech varieties proposed by Yule (2010), several components generally reflect and influence the meaning of each lexicon, those are, the participants are gay people; the setting or social context of the interaction is in the social media, public bar, house, or any place when they meet and/or having a conversation with the other speaker from the community; the topic is about preferences; and the functions are to know each other, deliver or exchange information, make a deal about sexual activities, and making a joke about something that relates to the speaker's preference.

\section{REFERENCES}

Adihartono, Wisnu. (2016). "Gaydar" atau "Gay Radar" : Sebuah "Bahasa" yang Bukan Bahasa. Jakarta : Universitas Indonesia.

American Psychological Association. (2008). Answers to your questions: For a better understanding of sexual orientation and homosexuality. Washington, DC: Author. Retrieved fromwww.apa.org/topics/sorientatio n.pdf.

Boellstorff,T. (2004). Gay Language and Indonesia : Registering Belonging. Journal of Linguistic Anthropology. Vol.14, Issue 2.
Butler, J. (2004). Undoing Gender. New York: Routledge.

Cage, K. (2003). From Moffietaal to Gayle - the evolution of a South African gay argot. Johannesburg, South Africa: s.n.

DeWalt, Kathleen M. \& DeWalt, Billie R. (2002). Participant observation: a guide for fieldworkers. Walnut Creek, CA: AltaMira Press.

Georgieva, M. (2014). Introducing Sociolinguistics. United Kingdom: University of Sofia Press.

Holmes, J. \& (2013). An Introduction to Sociolinguistics. 4th ed. London and New York: Routlegde.

Holmes, J. \& Wilson, N. (2017). An Introduction to Sociolinguistics. 5th ed. London and New York: Routlegde.

Kulick,D. (2000). Gay and Lesbian Language. Journal of Anthropology. Vol.29.

Lambert, V.A, \& Lambert, C.E. (2012). Editorial: Qualitative Descriptive Research: An Acceptable Design. Pacific Rim International Journal of Nursing Research. Vol.16, No.4.

Leap, William. (1995). Beyond the lavender lexicon: Aunthenticity, imagination, and Appropriation in Lesbian and Gay language. Luxembourg: Gordon and Brach.

Morgan, M. (2003). What are speech community? New York: Cambridge University Press.

Nassaji, H. (2015). Qualitative and Descriptive Research: Data Type Vs 
Data Analysis. Language Teaching Research. Vol 19, No. 2.

Oxford. 2017. Oxford Learner's Pocket Dictionary. 4th ed. New York: Oxford University Press.

Oxford. 2021. Chaser. Oxford Learner's Dictionaries. Retrieved from:Https://www.oxfordleranerdicti onaries.com/defenition/english/chase r.

Paradis, E. et al. (2016). "Design: Selection of Data collection Methods". Journal of Graduate Medical Education. Vol.8.

Ritchie, J., Lewis, J., \& Elam, G. (2003). Designing and selecting samples. In J. Ritchie \& J. Lewis (Eds.), Qualitative research practice: A guide for social science students and researchers. Book Section, London: Sage.

Rudwick, S. (2010). 'Gay and Zulu, we speak isiNgqumo': Ethnolinguistic identity constructions. Transformation: Critical Perspectives on Southern Africa, Vo. 1. Issue 74.

Yule, George. (2010). The Study of Language. New York: Cambridge University Press. 